\title{
Gas conditioning during helmet noninvasive ventilation: effect on comfort, gas exchange, inspiratory effort, transpulmonary pressure and patient-ventilator interaction
}

Filippo Bongiovanni ${ }^{1,2}$, Domenico Luca Grieco ${ }^{1,2^{*}}$ (D), Gian Marco Anzellotti ${ }^{1,2}$, Luca Salvatore Menga ${ }^{1,2}$, Teresa Michi ${ }^{1,2}$, Melania Cesarano ${ }^{1,2}$, Valeria Raggi 1,2, Cecilia De Bartolomeo ${ }^{1,2}$, Benedetta Mura 1,2, Giovanna Mercurio ${ }^{1,2}$, Sonia D'Arrigo ${ }^{1,2}$, Giuseppe Bello ${ }^{1,2}$, Riccardo Maviglia ${ }^{1,2}$, Mariano Alberto Pennisi ${ }^{1,2}$ and Massimo Antonelli, ${ }^{1,2}$

\begin{abstract}
Background: There is growing interest towards the use of helmet noninvasive ventilation (NIV) for the management of acute hypoxemic respiratory failure. Gas conditioning through heat and moisture exchangers (HME) or heated humidifiers ( $\mathrm{HHs}$ ) is needed during facemask NIV to provide a minimum level of humidity in the inspired gas (15 mg $\mathrm{H}_{2} \mathrm{O} / \mathrm{L}$ ). The optimal gas conditioning strategy during helmet NIV remains to be established.
\end{abstract}

Methods: Twenty patients with acute hypoxemic respiratory failure $\left(\mathrm{PaO}_{2} / \mathrm{FiO}_{2}<300 \mathrm{mmHg}\right)$ underwent consecutive 1-h periods of helmet NIV (PEEP $12 \mathrm{cmH}_{2} \mathrm{O}$, pressure support $12 \mathrm{cmH}_{2} \mathrm{O}$ ) with four humidification settings, applied in a random order: double-tube circuit with $\mathrm{HH}$ s and temperature set at $34^{\circ} \mathrm{C}(\mathrm{HH} 34)$ and $37^{\circ} \mathrm{C}(\mathrm{HH} 37)$; Y-piece circuit with HME; double-tube circuit with no humidification ( $\mathrm{NoH}$ ). Temperature and humidity of inhaled gas were measured through a capacitive hygrometer. Arterial blood gases, discomfort and dyspnea through visual analog scales (VAS), esophageal pressure swings $\left(\triangle P_{\mathrm{ES}}\right)$ and simplified pressure-time product (PTP $\mathrm{ES}_{\mathrm{ES}}$, dynamic transpulmonary driving pressure $\left(\triangle P_{\mathrm{L}}\right)$ and asynchrony index were measured in each step.

Results: Median [lqR] absolute humidity, temperature and VAS discomfort were significantly lower during $\mathrm{NoH}$ vs. $\mathrm{HME}, \mathrm{HH} 34$ and $\mathrm{HH} 37$ : absolute humidity $\left(\mathrm{mgH}_{2} \mathrm{O} / \mathrm{L}\right) 16$ [12-19] vs. 28 [23-31] vs. 28 [24-31] vs. 33 [29-38], $p<0.001$; temperature ( $\left.{ }^{\circ} \mathrm{C}\right) 29$ [28-30] vs. 30 [29-31] vs. 31 [29-32] vs 32. [31-33], $p<0.001$; VAS discomfort 4 [2-6] vs. 6 [2-7] vs. 7 [4-8] vs. $8[4-10], p=0.03$. VAS discomfort increased with higher absolute humidity $(p<0.01)$ and temperature $(p=0.007)$. Higher VAS discomfort was associated with increased VAS dyspnea $(p=0.001)$. Arterial blood gases, respiratory rate, $\triangle P_{E S}, P T P_{E S}$ and $\triangle P_{L}$ were similar in all conditions. Overall asynchrony index was similar in all steps, but autotriggering rate was lower during $\mathrm{NOH}$ and $\operatorname{HME}(p=0.03)$.

Conclusions: During 1-h sessions of helmet NIV in patients with hypoxemic respiratory failure, a double-tube circuit with no humidification allowed adequate conditioning of inspired gas, optimized comfort and improved

\footnotetext{
*Correspondence: dlgrieco@outlook.it

${ }^{1}$ Department of Anesthesiology and Intensive Care Medicine, Catholic

University of The Sacred Heart, Rome, Italy

Full list of author information is available at the end of the article
} 
patient-ventilator interaction. Use of HHs or HME in this setting resulted in increased discomfort due to excessive heat and humidity in the interface, which was associated with more intense dyspnea.

Trail Registration Registered on clinicaltrials.gov (NCT02875379) on August 23rd, 2016.

Keywords: Noninvasive ventilation, Respiratory Insufficiency, Humidity, Temperature

\section{Introduction}

The ongoing COVID-19 pandemic dramatically highlighted the role of noninvasive management of acute hypoxemic respiratory failure [1-3]. In hypoxemic respiratory failure, there is raising interest on the possible benefit of helmet noninvasive ventilation (NIV), since a growing body of evidence suggests physiological and clinical advantages over both facemask and high-flow nasal oxygen [4-8]. Putative benefits of this technique include the possibility of delivering long-term treatments with high levels of positive end-expiratory pressure (PEEP) [9-11], which improve hypoxemia, mitigate self-inflicted lung injury and may improve clinical outcome [12-14].

For helmet NIV, gas-compressed mechanical ventilators are necessary to provide the high inspiratory flows needed to wash out exhaled $\mathrm{CO}_{2}$ from the high devicerelated dead space [15]. When a compressed-gas ventilator is used, dry and cold air is delivered to the patient, while a minimum level of absolute humidity of $15 \mathrm{mgH}_{2} \mathrm{O} / \mathrm{L}$ has been shown to be necessary to avoid patients' discomfort and airway dryness during NIV [16]. Comfort and tolerability are key determinants of NIV success $[17,18]$. Thus, gas conditioning is recommended during facemask NIV with compressed-gas ventilators [19-28], either by heated humidifiers $(\mathrm{HH})$ or heat and moisture exchangers (HME), whose effects appear similar [16, 26-29]. These results may not be applicable to helmet NIV, as the interface is a $18-\mathrm{L}$ mixing chamber that allows some degree of gas heating and humidification by the patient himself; the few available data during helmet continuous positive airway pressure (CPAP) indicate that artificial conditioning of the inspired gas may be necessary only as the flow washing the system exceeds $30-35 \mathrm{~L} / \mathrm{min}[30,31]$. To our knowledge, no data ever assessed the effects during helmet pressure-support ventilation of the different strategies available for gas conditioning.

We conducted a randomized cross-over study to assess the effects of four different gas conditioning strategies during helmet pressure-support ventilation in hypoxemic patients, in terms of comfort, work of breathing, respiratory mechanics, patient-ventilator interaction and gas exchange.

\section{Methods}

This prospective, physiological, randomized, cross-over trial was conducted in the 20-bed general intensive care unit (ICU) of a university hospital in Italy between February 2017 and January 2019. Data analysis and manuscript drafting were delayed due to the COVID19 pandemic. The study protocol was approved by local ethics committee and prospectively registered on clinicaltrials.gov (NCT02875379). All enrolled patients provided written informed consent to participating in the trial and data analysis.

\section{Patients}

Non-hypercapnic adult patients deemed by the attending physician to require respiratory support due to acute hypoxemic respiratory failure $\left(\mathrm{PaO}_{2} / \mathrm{FiO}_{2}\right.$ ratio $<300$ ) were screened for the enrollment. Exclusion criteria were: exacerbation of asthma or chronic obstructive pulmonary disease; clinical evidence of acute cardiogenic pulmonary edema; hemodynamic instability (systolic blood pressure $<90 \mathrm{mmHg}$ or mean arterial pressure $<65 \mathrm{mmHg}$ ) and/or shock; metabolic acidosis ( $\mathrm{pH}<7.30$ with normo- or hypocapnia); hypercapnia $\left(\mathrm{PaCO}_{2}>45 \mathrm{mmHg}\right)$; Glasgow coma scale $<13$; recent gastric or abdominal surgery; non-collaborative patient.

\section{Interventions}

Study flow diagram is shown in Fig. 1.

Patients underwent helmet NIV through a dedicated interface (Dimar, Mirandola, Italy), whose size was chosen according to neck circumference [9]. Patients were connected to a pneumatic mechanical ventilator (Drager Evita XL or Evita Infinity, Lubeck, Germany) [32]. The ventilator was set in pressure-support mode with the following settings: initial pressure support 10-12 $\mathrm{cmH}_{2} \mathrm{O}$ and then adjusted to attain a peak inspiratory flow of $100 \mathrm{~L} / \mathrm{min}$, up to a maximum of $20 \mathrm{~cm} \mathrm{H}_{2} \mathrm{O}$; PEEP 10-12 $\mathrm{cmH} 2 \mathrm{O}$; flow trigger $2 \mathrm{~L} / \mathrm{min}$ and eventually increased in the presence of significant autotriggering; fastest pressurization time; expiratory trigger $30 \%$ of maximum inspiratory flow and eventually diminished in the case of double-triggering; maximum inspiratory time $1.0-1.2 \mathrm{~s}$. $\mathrm{FiO}_{2}$ was titrated to 


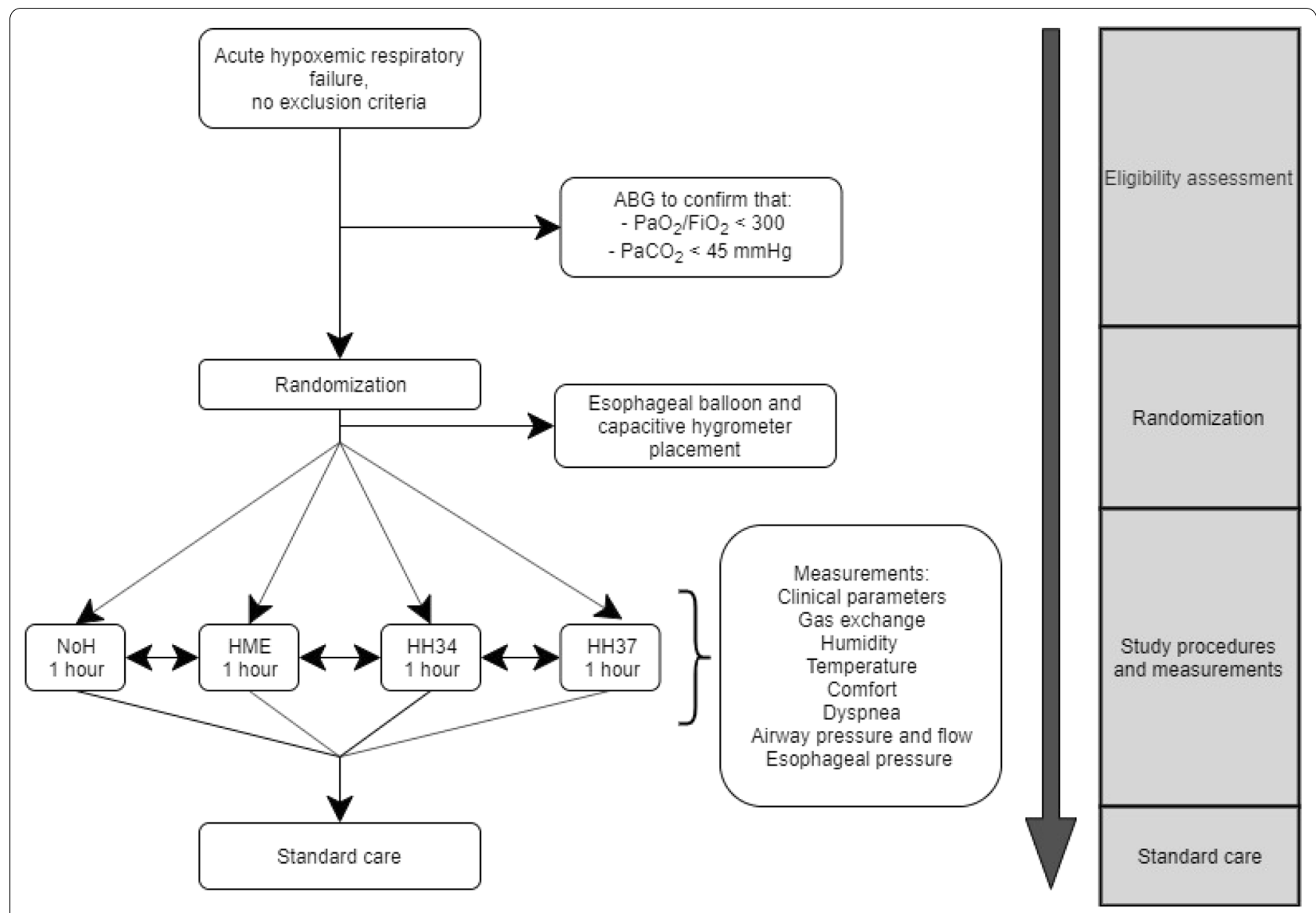

Fig. 1 Study flowchart

obtain as $\mathrm{SpO}_{2} \geq 92 \%$ and $\leq 98 \%$. These settings were kept unchanged during the study steps.

Each patient received four gas conditioning strategies (study steps) in a random order, for a duration of $1 \mathrm{~h}$ each (randomization was performed with SAS random allocation software and enrolled patients were assigned to the allocated sequence through sealed opaque envelopes) (Fig. 2):

- Heated humidification (MR860, Fisher and Paykel healthcare, New Zealand) with humidification chamber set at $34{ }^{\circ} \mathrm{C}$-double-tube circuit (HH34 step);

- Heated humidification (MR860, Fisher and Paykel healthcare, New Zealand) with humidification chamber set at $37{ }^{\circ} \mathrm{C}$-double-tube circuit (HH37 step);

- Passive humidification with a heat and moisture exchanger $\left(\mathrm{DAR}^{\mathrm{TM}}\right.$, Covidien, Medtronic, USA)standard circuit with Y-piece (HME step);

- No external humidification provided-double-tube circuit (NoH step).
To avoid any carry-on effect, between each step, patients received a 15-min washout period on oxygen therapy.

After enrollment, a polyfunctional nasogastric tube provided with an esophageal balloon (Nutrivent, Sidam, Italy) was placed to measure esophageal pressure $\left(\mathrm{P}_{\mathrm{ES}}\right)$. Because of the impossibility to perform Baydur maneuver in nonintubated patient [33-35], the esophageal balloon was filled with $4 \mathrm{ml}$ of air, which has been shown to be a non-stress volume providing reliability in a wide pressure range for this specific balloon [36]. To ensure intra-individual reproducibility, esophageal balloon was deflated and, after checking adequate zeroing, re-inflated before all measurements.

A capacitive hygrometer (Dimar, Mirandola, Italy) for measurement of absolute and relative humidity $(\mathrm{AH}$ and $\mathrm{RH}$ ) and temperature was positioned inside the helmet through a dedicated port. The device was calibrated before all measurements. 


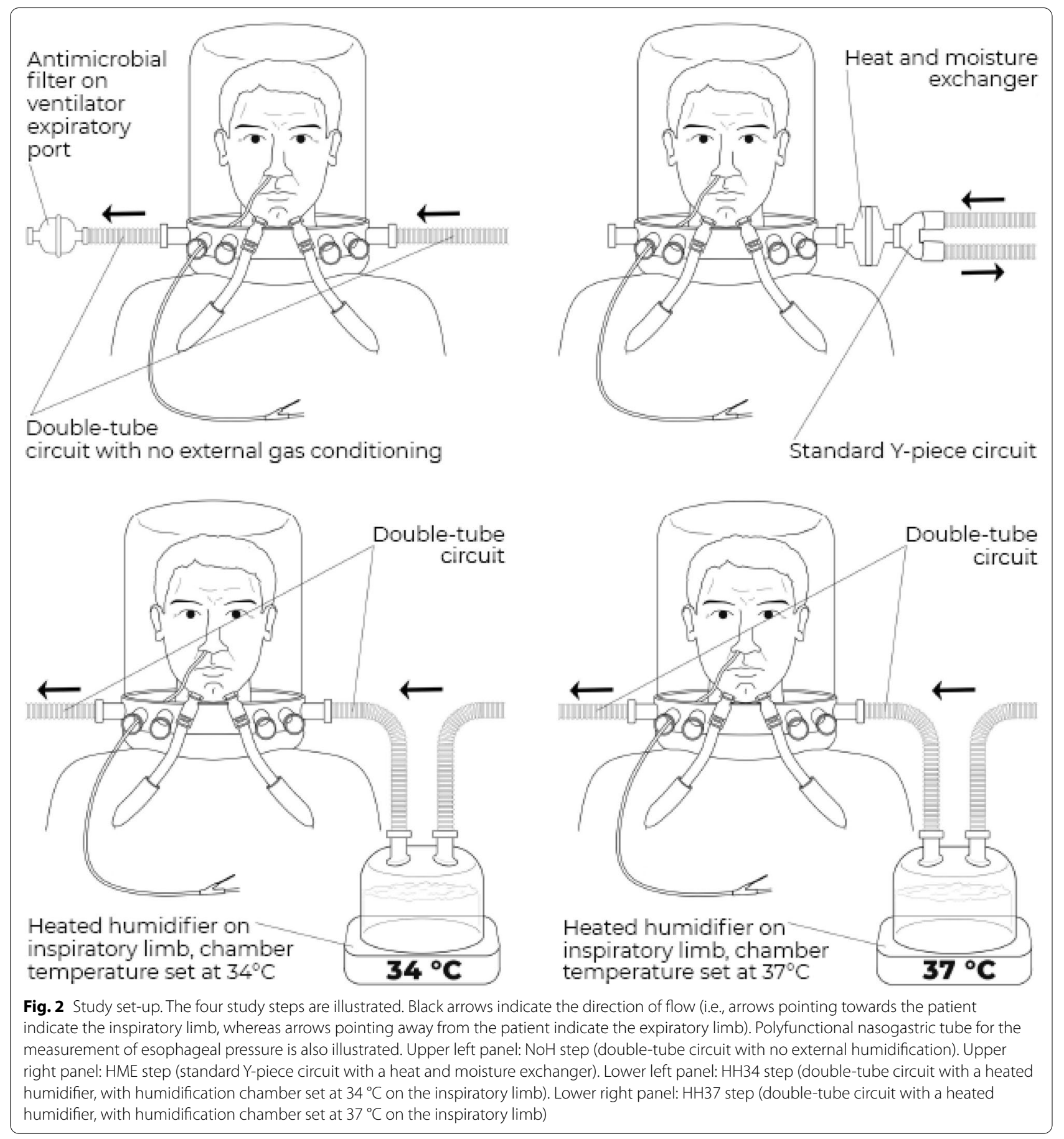

\section{Measurements}

Patient's demographic and clinical characteristics and baseline room temperature and humidity were collected at study entry. During the study, patients received standard ICU monitoring (5-lead electrocardiogram, invasive blood pressure and $\mathrm{SpO}_{2}$ ).
At the end of each study step, clinical parameters (heart rate, arterial blood pressure, $\mathrm{SpO}_{2}$,) and arterial blood gases were collected, and patients were asked to rate the degree of dyspnea and device-related discomfort according to visual analog scales (VAS) for critically ill patients [5]. The examiner subjectively visually evaluated the 
presence and degree of condensation inside the helmet ("fog effect") according to a 1-to-3 observation scale.

At the end of each step, after a stable breathing pattern was established and after ensuring stability of humidity and temperature measurements, a pressure transducer measured (sampling rate $=200 \mathrm{~Hz}$ ) $P_{\mathrm{ES}}$ and a Fleischtype pneumotachograph (n.2, Metabo, Lausanne, Switzerland) measured inspiratory flow and airway pressure (Paw). All signals were amplified, low-pass filtered, digitalized and transmitted to a personal computer with dedicated softwares for waveforms analysis (ICU Lab, Kleistek, Bari, Italy) and temperature and humidity data analysis (Humidity Dimar, E +E Elektronik Ges.m.b.H, Austria). All data from this recording were analyzed and results were averaged for each study step.

$P_{\text {ES }}$, Paw and flow tracings where then reviewed offline and the following parameters were computed for each step:

- Respiratory mechanics and work of breathing indices: patient's respiratory rate (number of negative deflections of $P_{\mathrm{ES}}$ per minute); ventilator respiratory rate (number of ventilator-delivered breaths per minute); inspiratory effort $\left(\triangle P_{\mathrm{ES}}\right.$, the negative inspiratory swing of $P_{\mathrm{ES}}$ ); simplified $P_{\mathrm{ES}}$ pressure-time product per breath $\left(\mathrm{PTP}_{\mathrm{ES}}\right.$ : area under the curve of esophageal pressure during inspiration, chest wall recoil pressure was neglected due to the impossibility of performing occlusions, $P_{\mathrm{ES}}$ ) and per minute; dynamic transpulmonary driving pressure $\left(\Delta P_{\mathrm{L}}\right.$, the positive tidal swing in transpulmonary pressure, calculated as the difference between airway pressure and $P_{\mathrm{ES}}$ ) [5, $34,35,37] . \Delta P_{\mathrm{L}}$, albeit primarily influenced by tidal volume, also includes a resistive component due to airflow; we assumed that resistive pressure did not change significantly between the four study steps, thus allowing to take $\Delta P_{\mathrm{L}}$ as a surrogate for transpulmonary driving pressure.

- Patient-ventilator synchrony: the following asynchronies were diagnosed by in-phase reading of esophageal and airway tracings [35, 38, 39], according to existing definitions and diagnostic criteria [3941]:

- Ineffective efforts: negative flexion of esophageal pressure (i.e., active inspiratory effort) without a corresponding delivery of a mechanical breath by the ventilator.

- Autotriggering: delivery of a mechanical breath by the ventilator without a corresponding negative flexion of esophageal pressure.

- Double cycling: delivery of two mechanical breaths by the ventilator corresponding to a single continuing negative flexion of esophageal pressure.

- Premature expiratory cycling: termination of a mechanical breath delivered by the ventilator (as assessed by the flow tracing) preceding the end of the corresponding patient's active inspiratory effort as assessed by the esophageal pressure tracing.

The overall burden of asynchronies was assessed by the asynchrony index, defined as the total number of asynchronies divided by the total respiratory rate (computed as the sum of the number of ventilator-delivered breaths, triggered or not, and ineffective efforts). Inspiratory and expiratory trigger delay asynchronies were not considered, since helmet NIV is known to be characterized by significant physiological trigger delays due to the compliance of the interface and its associated slow internal pressure buildup and decay $[5,11,42]$.

For all calculations, start of inspiration was determined at the instant of $P_{\mathrm{ES}}$ initial decay, and end of inspiration was determined at the point of the respiratory cycle where $25 \%$ of time elapsed from $P_{\mathrm{ES}}$ maximal negative deflection towards its return to baseline [43].

\section{Endpoints}

Primary endpoints were VAS discomfort, work of breathing indices and patient-ventilator synchrony. Main secondary endpoints were: humidity and temperature inside the interface, degree of fog effect, VAS dyspnea, respiratory rate, expired helmet minute volume, dynamic transpulmonary driving pressure.

\section{Sample size calculation}

Given the physiological design of the study, we did not perform a formal sample size calculation. Consistent with previous investigations on the topic with similar endpoints [16, 30, 31], we planned to enroll 20 patients.

\section{Statistical analysis}

Qualitative data are expressed as number of events (\%) and continuous data as median [interquartile range]. Ordinal qualitative variables and non-normal quantitative variables distributions in the four study step were compared with the Wilcoxon/Kruskal-Wallis sum of rank test. Paired comparisons between steps were performed with the Wilcoxon test. All analysis was performed applying a bilateral hypothesis and results with $p \leq 0.05$ were considered significant. Statistical analysis was performed with JMP ${ }^{\circledR}$ Pro, Version 13 (SAS Institute Inc., Cary, NC, USA). Manuscript figures were prepared with GraphPad Prism (GraphPad Software, La Jolla, CA USA). 
Table 1 Demographics and baseline characteristics of enrolled patients

\begin{tabular}{|c|c|}
\hline Age, years & $72[64-77]$ \\
\hline Female sex, no. (\%) & $7(35 \%)$ \\
\hline Height, $\mathrm{cm}$ & $168[161-170]$ \\
\hline Body mass index, $\mathrm{kg} / \mathrm{m}^{2}$ & $28[24-29]$ \\
\hline Ideal body weight, kg & $64[57-66]$ \\
\hline SAPS II & $43[34-51]$ \\
\hline SOFA at study inclusion & $4[3-8]$ \\
\hline \multicolumn{2}{|l|}{ Reason for ICU admission, no. (\%) } \\
\hline Medical & $20(100 \%)$ \\
\hline Surgical & $0(0 \%)$ \\
\hline \multicolumn{2}{|l|}{ Cause of respiratory failure, no. (\%) } \\
\hline Pulmonary, infectious & $13(65 \%)$ \\
\hline Pulmonary, non-infectious & $5(25 \%)$ \\
\hline Extrapulmonary & $2(10 \%)$ \\
\hline Length of noninvasive respiratory support before enrollment, hours & $0[0-14]$ \\
\hline \multicolumn{2}{|l|}{ Baseline respiratory support device at enrollment, no. (\%) } \\
\hline Venturi mask & $1(5 \%)$ \\
\hline High-flow nasal oxygen & $16(80 \%)$ \\
\hline Facemask noninvasive ventilation & $1(5 \%)$ \\
\hline Helmet noninvasive ventilation & $2(10 \%)$ \\
\hline \multicolumn{2}{|l|}{ Characteristics at enrollment } \\
\hline $\mathrm{PaO}_{2} / \mathrm{FiO}_{2}$ ratio, $\mathrm{mmHg}$ & $169[112-279]$ \\
\hline $\mathrm{PaCO}_{2}, \mathrm{mmHg}$ & $33[29-35]$ \\
\hline $\mathrm{pH}$ & $7.45[7.41-7.50]$ \\
\hline Heart rate, bpm & $91[81-109]$ \\
\hline Mean arterial pressure, mmHg & $93[84-103]$ \\
\hline Room temperature, ${ }^{\circ} \mathrm{C}$ & $25[24,25]$ \\
\hline Room absolute humidity, $\mathrm{mgH}_{2} \mathrm{O} / \mathrm{L}$ & $11[9-12]$ \\
\hline Room relative humidity, $\%$ & $50[41-52]$ \\
\hline Sedation/analgesia during the study*, no. (\%) & $3(15 \%)$ \\
\hline Glasgow coma scale at study inclusion & $15[15-15]$ \\
\hline Need for endotracheal intubation, no. (\%) & $9(45 \%)$ \\
\hline In-intensive care unit mortality, no. (\%) & $7(35 \%)$ \\
\hline
\end{tabular}

Data are expressed as median [interquartile range], if not otherwise specified

* Two patients received remifentanil continuous infusion during the study, without dosage changes over the course of the study

\section{Results}

Twenty patients were included. Patients' demographic and baseline most relevant clinical features are shown in Table 1; main results of the study are displayed in Table 2.

\section{Gas exchange}

Median [interquartile range] $\mathrm{PaO}_{2} / \mathrm{FiO}_{2}$ ratio at enrollment was $169 \mathrm{mmHg}$ [112-279]. No differences in $\mathrm{PaO}_{2} / \mathrm{FiO}_{2}, \mathrm{PaCO}_{2}, \mathrm{pH}$, heart rate and mean arterial pressure were detected between the study steps (Table 2).

\section{Gas conditioning}

These results are shown in Table 2 and Fig. 3. Absolute humidity, relative humidity and temperature inside the helmet interface were significantly lower when the $\mathrm{NoH}$ strategy was applied (all $p<0.001$ ), displaying an increasing trend from the steps $\mathrm{NoH}$ to HME to HH34 to HH37. Median absolute humidity was above $15 \mathrm{mgH}_{2} \mathrm{O} / \mathrm{L}$ in all steps, notably being 16 [12-19] $\mathrm{mgH}_{2} \mathrm{O} / \mathrm{L}$ in the $\mathrm{NoH}$ step.

\section{Self-assessed symptoms and fog effect}

These results are shown in Table 2 and Fig. 3. VAS discomfort and observator-assessed fog effect were lower in the $\mathrm{NoH}$ step, increasing towards the 
Table 2 Main results of the study

\begin{tabular}{|c|c|c|c|c|c|}
\hline & $\mathrm{NoH}$ & HME & HH34 & HH37 & $\mathrm{p}$ \\
\hline \multicolumn{6}{|l|}{ Gas exchange } \\
\hline $\mathrm{PaO}_{2} / \mathrm{FiO}_{2}$ ratio, $\mathrm{mmHg}$ & $260[216-320]$ & $252[207-317]$ & $232[188-303]$ & 234 [201-292] & 0.73 \\
\hline $\mathrm{PaCO}_{2}, \mathrm{mmHg}$ & $30[28-36]$ & $34[30-37]$ & $31[29-35]$ & $34[29-38]$ & 0.46 \\
\hline $\mathrm{pH}$ & $7.47[7.42-7.49]$ & $7.44[7.41-7.48]$ & $7.46[7.42-7.49]$ & $7.47[7.41-7.49]$ & 0.73 \\
\hline \multicolumn{6}{|l|}{ Gas conditioning, self-assessed symptoms and fog effect } \\
\hline Absolute humidity, $\mathrm{mgH}_{2} \mathrm{O} / \mathrm{L}$ & $16[12-19]^{a \beta \gamma}$ & $28[23-31]^{a \varepsilon}$ & $28[24-31]^{\beta \zeta}$ & $33[29-38]^{\mathrm{Y}^{\zeta}}$ & $<0.001$ \\
\hline Relative humidity, $\%$ & $52[40-63]^{a \beta \gamma}$ & $92[81-97]^{a \varepsilon}$ & $96[83-100]^{\beta}$ & $100[93-100]^{\gamma \varepsilon}$ & $<0.001$ \\
\hline Helmet temperature, ${ }^{\circ} \mathrm{C}$ & $29[28-30]^{\alpha}$ & $30[29-31]^{\varepsilon}$ & $31[29-32]^{\zeta}$ & $32[31-33]^{\alpha \varepsilon \zeta}$ & $<0.001$ \\
\hline Dyspnea, VAS & $2[1-5]$ & $3[1-5]$ & $4[1-5]$ & $4[1-7]$ & 0.46 \\
\hline Discomfort, VAS & $4[2-6]^{\gamma}$ & $6[2-7]$ & $7[4-8]$ & $8[4-10]^{\gamma}$ & 0.03 \\
\hline Fog effect, 1-3 scale & $0[0-0]^{\alpha \beta \gamma}$ & $1[1-3]^{\alpha \varepsilon}$ & $2[1-3]^{\beta \zeta}$ & $3[3-3]^{\gamma \zeta}$ & $<0.001$ \\
\hline \multicolumn{6}{|l|}{ Respiratory mechanics and work of breathing indices } \\
\hline Patient respiratory rate, bpm & $26[22-31]$ & $26[22-32]$ & $27[21-33]$ & $26[22-31]$ & 0.99 \\
\hline Ventilator respiratory rate, bpm & $31[27-36]$ & $31[25-34]$ & $32[24-34]$ & 30 [23-33] & 0.43 \\
\hline Helmet minute ventilation, $L^{*} \min ^{-1}$ & $21[20-27]$ & $19[16-24]^{\delta \varepsilon}$ & $27[23-30]^{\delta}$ & $24[20-32]^{\varepsilon}$ & 0.009 \\
\hline$\Delta P_{\mathrm{ES}} \mathrm{CmH}_{2} \mathrm{O}$ & $7[4-9]$ & $9[5-11]$ & $6[4-10]$ & $7[5-11]$ & 0.54 \\
\hline$\Delta P_{L^{\prime}} \mathrm{CmH} 2 \mathrm{O}$ & $21[17-23]$ & $17[15-21]$ & 20 [18-23] & $21[16-24]$ & 0.21 \\
\hline PTP $_{E S}$ per minute, $\mathrm{CmH} 2 \mathrm{O}^{*} \mathrm{sec}^{*} \mathrm{~min}^{-1}$ & $82[40-127]$ & $109[32-172]$ & 74 [34-137] & $61[39-112]$ & 0.74 \\
\hline \multicolumn{6}{|l|}{ Patient-ventilator asynchronies } \\
\hline Asynchrony index (Al), \% & $19[4-51]$ & $7[2-33]$ & $18[5-35]$ & $16[4-40]$ & 0.78 \\
\hline Ineffective efforts, \% & $1[0-2]$ & $1[0-2]$ & $1[0-5]$ & $2[0-6]$ & 0.55 \\
\hline Proportion of Al due to ineffective efforts, $\%$ & $14[0-71]$ & $15[0-63]$ & $19[0-64]$ & $22[0-61]$ & 0.99 \\
\hline Double cycling, $\%$ & $1[0-5]^{a}$ & $0[0-1]^{\alpha \varepsilon}$ & $0[0-3]$ & $1[0-3]^{\varepsilon}$ & 0.05 \\
\hline Proportion of Al due to double cycling, $\%$ & $7[0-30]^{a}$ & $0[0-7]^{a \varepsilon}$ & $0.3[0-12]$ & $11[0-26]^{\varepsilon}$ & 0.07 \\
\hline Premature expiratory cycling, $\%$ & $7[1-40]$ & $2[0-19]$ & $6[0-16]$ & $4[0-14]$ & 0.72 \\
\hline Proportion of Al due to premature expiratory cycling, $\%$ & $42[9-80]$ & $24[0-74]$ & $22[6-56]$ & $21[13-56]$ & 0.66 \\
\hline Autotriggering, $\%$ & $0[0-1]^{\beta \gamma}$ & $0[0-2]^{\delta}$ & $1[0-8]^{\beta \delta}$ & $1[0-6]^{\gamma}$ & 0.03 \\
\hline Proportion of Al due to autotriggering, $\%$ & $0[0-2]^{\beta \gamma}$ & $2[0-30]$ & $14[2-28]^{\beta}$ & $16[3-39]^{\gamma}$ & 0.01 \\
\hline \multicolumn{6}{|l|}{ Hemodynamics } \\
\hline Heart rate, bpm & $83[80-109]$ & $90[75-108]$ & $90[75-108]$ & $90[76-106]$ & 0.98 \\
\hline Mean arterial pressure, $\mathrm{mmHg}$ & $87[73-104]$ & $88[78-106]$ & $88[72-101]$ & 83 [74-103] & 0.61 \\
\hline
\end{tabular}

Data are expressed as median [interquartile range]

$a$ indicates a $\mathrm{p}<0.05$ for paired comparisons between $\mathrm{NoH}$ and $\mathrm{HME}$ $\beta$ indicates a $p<0.05$ for paired comparisons between $\mathrm{NoH}$ and $\mathrm{HH} 34$ $\gamma$ indicates a $p<0.05$ for paired comparisons between $\mathrm{NoH}$ and $\mathrm{HH} 37$ $\delta$ indicates a $\mathrm{p}<0.05$ for paired comparisons between $\mathrm{HME}$ and $\mathrm{HH} 34$ $\varepsilon$ indicates a $\mathrm{p}<0.05$ for paired comparisons between $\mathrm{HME}$ and $\mathrm{HH} 37$ $\zeta$ indicates a $\mathrm{p}<0.05$ for paired comparisons between $\mathrm{HH} 34$ and $\mathrm{HH} 37$

higher-humidification steps $(p=0.03$ and $p<0.001$, respectively). VAS dyspnea was not significantly different between the study steps $(p=0.46)$. Across all study steps (all measurements taken into account), VAS discomfort increased at raising levels of absolute humidity $(p<0.001)$ and temperature $(p=0.007)$, as displayed in Fig. 4. Higher discomfort was associated to higher dyspnea ( $p=0.001-$ Fig. 4$)$.

\section{Respiratory mechanics and work of breathing}

These results are displayed in Table 2. Neither patient nor ventilator respiratory rate were different between the study steps ( $p=0.99$ and $p=0.43$, respectively). Total minute ventilation (i.e., the total system minute fresh gas flow) was slightly higher in HH34 and HH37 when compared to the non-actively humidified steps $(p=0.009)$. The analyzed work of breathing indices $\left(\Delta P_{\mathrm{ES}}\right.$, dynamic transpulmonary driving pressure and simplified esophageal $\mathrm{PTP}_{\mathrm{ES}}$ ) along with $\Delta P_{\mathrm{L}}$ did not differ between steps. 


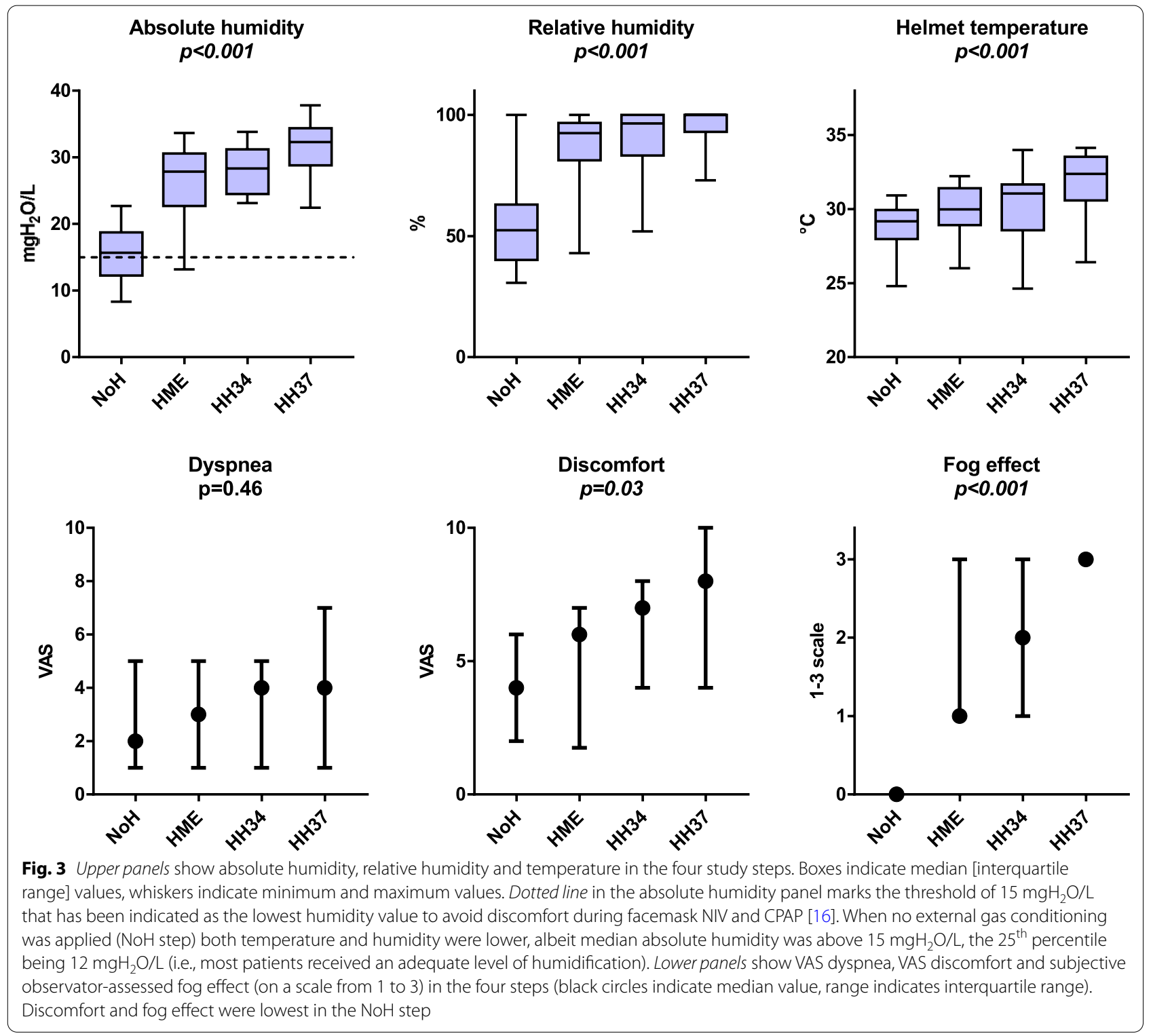

\section{Patient-ventilator interaction}

As shown in Table 2, the asynchrony index was not significantly different between the four steps $(p=0.78)$, with a median asynchrony index of 16\% [4-40\%]. Overall, the most represented asynchrony was premature expiratory cycling, with an index of $4 \%$ when all measurements were taken into account [0-16\%]. The rate of autotriggering, albeit low in all steps, was significantly higher in HH34 and HH37 steps $(p=0.03)$.

\section{Discussion}

The main results of this randomized cross-over physiological study on gas conditioning during helmet pressure-support NIV can be summarized as follows:
1. Levels of humidity and temperature are significantly lower when no external gas conditioning is applied, when compared with the use of HME or HHs. Even with a $\mathrm{NoH}$ strategy, most patients are above the absolute humidity threshold of $15 \mathrm{mgH}_{2} \mathrm{O} / \mathrm{L}$, which has been described as the minimum required humidification during NIV [16].

2. Subjective discomfort is lower when a double-tube circuit with no humidification is used, as it is the formation of fog effect inside the interface.

3. Overall, discomfort increased at raising levels of humidity and temperature, provided that the great majority of measurements above or around the abovementioned safety margin of $15 \mathrm{mgH}_{2} \mathrm{O} / \mathrm{L}$. 


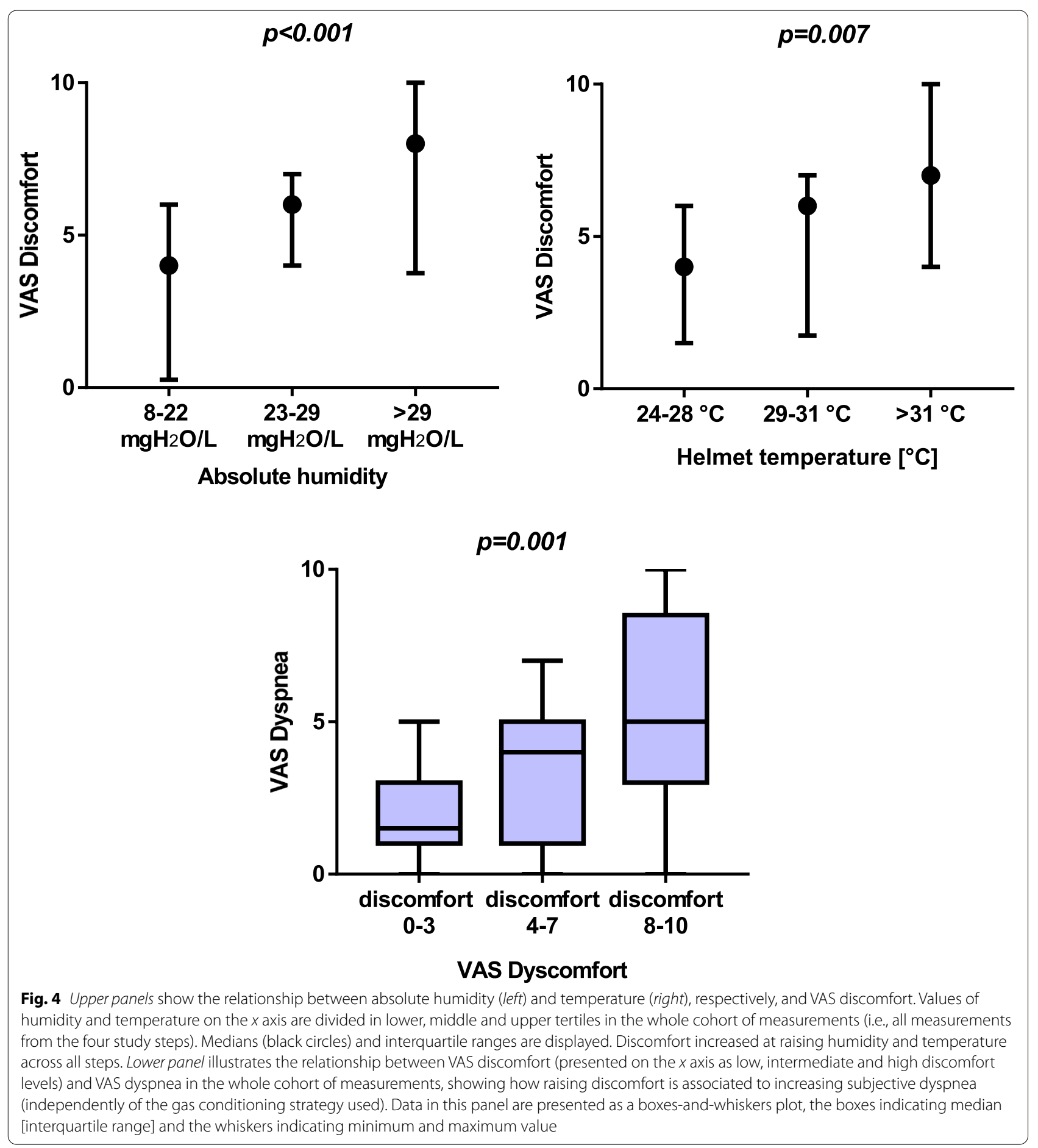

Increasing levels of discomfort appear to be related to worsening dyspnea in these patients.

4. The gas conditioning strategy does not appear to influence overall patient-ventilator synchrony, with the exception of an increased rate of autotriggering when $\mathrm{HHs}$ are used.
5. Respiratory rate, inspiratory effort, dynamic transpulmonary driving pressure and work of breathing are not affected by the gas conditioning strategy used. A slightly increased total helmet minute ventilation is seen when heated humidification is applied. 
Two studies addressed the issue of gas conditioning during helmet continuous positive airway pressure (CPAP), and showed that humidification and comfort were optimal when no gas conditioning strategy was used during ventilator-delivered CPAP, while the application of a $\mathrm{HH}$ was needed at high continuous fresh gas flows $\left(>40 \mathrm{~L} \mathrm{~min}{ }^{-1}\right.$ ) with a PEEP valve [30,31]. Notably, ventilator-delivered CPAP implies a lower fresh gas flow than continuous-flow CPAP, usually below the threshold of 30 $\mathrm{L} \mathrm{min}^{-1}$, which is the minimum value of fresh gas flow suggested to avoid $\mathrm{CO}_{2}$ retention in the interface and significant rebreathing [15].

No previous data exist regarding the optimal gas conditioning strategy during helmet pressure-support ventilation, where system washout flow is equal or slightly superior to the system minute ventilation, typically lower than during high-flow CPAP but higher than during ventilator-delivered CPAP. This implies that existing data on helmet CPAP cannot be extrapolated to the setting of helmet pressure-support ventilation.

Our study demonstrates that, during helmet pressuresupport ventilation, a double-tube circuit with no humidification allows adequate conditioning of the inspired gas, improves patient's comfort and, when compared to active conditioning through heated humidifiers, may reduce ventilator autotriggering. Patient's comfort appeared essential to prevent dyspnea. Both dyspnea and discomfort are important factors for successful noninvasive ventilation and avoiding the need for endotracheal intubation $[17,18,44-47]$.

Helmet NIV is receiving growing attention and is being proposed as a first-line strategy in the noninvasive management of acute hypoxemic respiratory failure, as it may have physiological advantages and improve outcomes over facemask NIV and high-flow nasal oxygen [4-8]. Our study shines light on the rather unexplored but relevant issue of gas conditioning in the specific setting of helmet NIV and its effects on comfort and other patientcentered outcomes.

Our data indicate that an adequate minimal level of humidification is provided with all strategies during helmet NIV, including the absence of external gas conditioning. This is likely due to the relatively low total system washout flow (in all steps median helmet minute ventilation was below $30 \mathrm{~L} / \mathrm{min}$ ) when compared to high-flow CPAP, where usual flows range around $50 \mathrm{~L} / \mathrm{min}$ : this allows the helmet interface to efficiently work as a mixing chamber where patient's expired air directly contributes to the heating and humidification of ventilator-delivered dry inspired gas, without being massively washed-out as in high-flow CPAP [30]. Provided that minimal acceptable gas conditioning is guaranteed, our data indicate that excessive humidity and temperature may generate discomfort [31]: in our cohort over-humidification, rather than under-humidification, appeared to be related to patients' discomfort. This explains the worsening discomfort when heated humidifiers are applied in this setting. Importantly, reduction of discomfort mediates concurrent reductions in the dyspnea score.

The gas conditioning strategy does not appear to influence gas exchange, work of breathing and overall patient-ventilator interaction (as measured by the asynchrony index). When individual asynchronies were analyzed, a small increase in the autotriggering rate with heated humidifiers was apparent, likely due to increased water condensation in the inspiratory limb of the circuit [48].

Despite the physiological nature of the study, our results may have relevant clinical implications. During helmet pressure-support noninvasive ventilation in hypoxemic patients, a double-tube circuit with no external humidification applied may be an acceptable gas conditioning strategy, since it does not affect work of breathing and oxygenation and appears to improve patient's comfort and patient-ventilator interaction.

Our study has limitations:

1. The duration of each study step was limited to $1 \mathrm{~h}$, which may preclude generalizability of the results to patients subjected to longer NIV treatments. Specifically, such a limited time could be insufficient to accurately assess respiratory discomfort directly related to higher airway dryness in case of underhumidification. However, study measurements were taken at the end of the 60-min periods after ensuring stability of physiological data, and the randomized cross-over design with 60-min consecutive periods of the present investigation is consistent with previous studies comparing different gas conditioning systems during CPAP or NIV with similar physiological endpoints [16, 28-30, 49]. We believe that this makes the results of our manuscript reproducible for longerterm treatments.

2. The small sample size may have precluded the possibility to draw specific conclusions on secondary outcome measures and particularly subgroup analyses. Nevertheless, similar sample sizes have been selected for physiological studies focusing on similar outcomes, and results on the primary outcomes show a strong statistical significance.

3. $\mathrm{PaO}_{2} / \mathrm{FiO}_{2}$ ratio, albeit below $300 \mathrm{mmHg}$, varies significantly between patients, with a relevant proportion of patients exhibiting mild hypoxemia $\left(\mathrm{PaO}_{2} /\right.$ $\mathrm{FiO}_{2}$ between 200 and 300). This may have diluted the sample of moderate-to-severe patients, which are expected to display higher inspiratory effort and 
total minute ventilation: it is possible that a sample of more severe patients with higher helmet minute ventilation could reach higher median washout flows, possibly exceeding $30-40 \mathrm{~L} / \mathrm{min}$ and thus physiologically resembling the abovementioned condition of high-flow CPAP [30]. In such a setting, our conclusions may not be applicable, as the risk of underhumidification could dictate the use of external gas conditioning strategies.

\section{Conclusion}

During helmet pressure support NIV, a double-tube circuit with no external gas conditioning ensures adequate humidity and heat of the inspired gas, improves comfort and patient-ventilator interaction. Use of HHs or HME in this setting may generate excessive humidity and heat in the interface, finally increasing discomfort, which is associated to worse dyspnea.

\section{Abbreviations}

ICU: Intensive care unit; NIV: Noninvasive ventilation; PEEP: Positive end-expiratory pressure; $\mathrm{HH}$ : Heated humidifier; $\mathrm{NoH}$ : No humidification; HME: Heat and moisture exchanger; $\triangle P_{L}$ : Dynamic transpulmonary driving pressure; $\triangle P_{E S}$ Esophageal pressure inspiratory swing; PTP $_{E S}$ : Esophageal pressure inspiratory pressure-time product.

\section{Acknowledgements}

The authors are grateful to Gabriele Esposito, PhD, for drafting Figure 2

\section{Authors' contributions}

DLG, FB and MA designed the study. FB, GMA, LSM, VR, BM, GM, SDA and RM conducted the study on enrolled patients. FB, LSM, TM, MC, CDB and DLG analyzed the data. FB and DLG drafted the first draft of the manuscript. GB, RM, MAP and MA interpreted the results and revised the first draft of the manuscript. MA organized the study as an overall supervisor. All the authors approved the final version of the manuscript and agreed on submitting it to Annals of Intensive Care. All authors read and approved the final manuscript.

\section{Funding statement}

This work is supported by a research Grant by SIAARTI (2017 MSD award).

\section{Availability of data and materials}

The datasets used and/or analyzed during the current study are available from the corresponding author on reasonable request.

\section{Declarations}

\section{Ethics approval and consent to participate}

The study was approved by local Ethics Committee and informed consent was obtained by enrolled patients according to committee recommendation.

\section{Consent for publication}

Not applicable.

\section{Competing interests}

DLG has received payments for travel expenses by Maquet, Getinge and Air Liquide. MA has received payments for Board participation from Maquet, Air Liquide and Chiesi. DLG and MA disclose a research grant by General Electric Healthcare.

\section{Author details}

${ }^{1}$ Department of Anesthesiology and Intensive Care Medicine, Catholic University of The Sacred Heart, Rome, Italy. ${ }^{2}$ Anesthesia, Emergency and Intensive Care Medicine, Fondazione Policlinico Universitario A. Gemelli IRCCS, L.Go F. Vito, 00168 Rome, Italy.

Received: 7 October 2021 Accepted: 12 December 2021

Published online: 24 December 2021

References

1. Rochwerg B, Brochard L, Elliott MW, Hess D, Hill NS, Nava S, et al. Official ERS/ATS clinical practice guidelines: noninvasive ventilation for acute respiratory failure. Eur Respir J. 2017. https://doi.org/10.1183/13993003. 02426-2016.

2. Gorman E, Connolly B, Couper K, Perkins GD, McAuley DF. Non-invasive respiratory support strategies in COVID-19. Lancet Respir Med. 2021;9:553-6.

3. Grieco DL, Maggiore SM, Roca O, Spinelli E, Patel BK, Thille AW, et al. Non-invasive ventilatory support and high-flow nasal oxygen as first-line treatment of acute hypoxemic respiratory failure and ARDS. Intensive Care Med. 2021;47:851-66.

4. Patel BK, Wolfe KS, Pohlman AS, Hall JB, Kress JP. Effect of noninvasive ventilation delivered by helmet vs face mask on the rate of endotracheal intubation in patients with acute respiratory distress syndrome. JAMA. 2016;315:2435-41.

5. Grieco DL, Menga LS, Raggi V, Bongiovanni F, Anzellotti GM, Tanzarella ES, et al. Physiological comparison of high-flow nasal cannula and helmet noninvasive ventilation in acute hypoxemic respiratory failure. Am J Respir Crit Care Med. 2020;201:303-12.

6. Ferreyro BL, Angriman F, Munshi L, Del Sorbo L, Ferguson ND, Rochwerg $B$, et al. Association of noninvasive oxygenation strategies with all-cause mortality in adults with acute hypoxemic respiratory failure. JAMA [Internet]. 2020;324:57. https://jamanetwork.com/journals/jama/fullarticle/ 2767025

7. Grieco DL, Menga LS, Cesarano M, Rosà T, Spadaro S, Bitondo MM, et al. Effect of helmet noninvasive ventilation vs high-flow nasal oxygen on days free of respiratory support in patients with COVID-19 and moderate to severe hypoxemic respiratory failure: The HENIVOT randomized clinical trial. JAMA. 2021;325:1731-43.

8. Chaudhuri D, Jinah R, Burns KEA, Angriman F, Ferreyro B, Munshi L, et al. Helmet non-invasive ventilation compared to facemask non-invasive ventilation and high flow nasal cannula in acute respiratory failure: a systematic review and meta-analysis. Eur Respir J. 2021. https://doi.org/ 10.1183/13993003.01269-2021.

9. Antonelli M, Conti G, Pelosi P, Gregoretti C, Pennisi MA, Costa R, et al. New treatment of acute hypoxemic respiratory failure: noninvasive pressure support ventilation delivered by helmet-a pilot controlled trial. Crit Care Med. 2002;30:602-8.

10. Vargas F, Thille A, Lyazidi A, Campo FR, Brochard L. Helmet with specific settings versus facemask for noninvasive ventilation. Crit Care Med. 2009:37:1921-8.

11. Mojoli F, lotti GA, Currò I, Pozzi M, Via G, Venti A, et al. An optimized set-up for helmet noninvasive ventilation improves pressure support delivery and patient-ventilator interaction. Intensive Care Med. 2013;39:38-44.

12. Liu Q, Gao Y, Chen R, Cheng Z. Noninvasive ventilation with helmet versus control strategy in patients with acute respiratory failure: a systematic review and meta-analysis of controlled studies. Crit Care. 2016;20:265.

13. Yoshida T, Fujino Y, Amato MBP, Kavanagh BP. Fifty years of research in ARDS. Spontaneous breathing during mechanical ventilation. Risks, mechanisms, and management. Am J Respir Crit Care Med. 2017;195:985-92.

14. Morais CCA, Koyama Y, Yoshida T, Plens GM, Gomes S, Lima CAS, et al. High positive end-expiratory pressure renders spontaneous effort noninjurious. Am J Respir Crit Care Med. 2018;197:1285-96.

15. Taccone P, Hess D, Caironi P, Bigatello LM. Continuous positive airway pressure delivered with a "helmet": effects on carbon dioxide rebreathing. Crit Care Med. 2004;32:2090-6. 
16. Lellouche F, Maggiore SM, Lyazidi A, Deye N, Taillé S, Brochard L. Water content of delivered gases during non-invasive ventilation in healthy subjects. Intensive Care Med. 2009;35:987-95.

17. Mehta S, Hill NS. Noninvasive ventilation. Am J Respir Crit Care Med 2001;163:540-77. https://doi.org/10.1164/ajrccm.163.2.9906116.

18. Nava $\mathrm{S}$, Hill N. Non-invasive ventilation in acute respiratory failure. Lancet. 2009;374:250-9.

19. Nava S, Navalesi P, Gregoretti C. Interfaces and humidification for noninvasive mechanical ventilation. Respir Care. 2009;54:71-84.

20. Esquinas Rodriguez AM, Scala R, Soroksky A, BaHammam A, de Klerk A, Valipour A, et al. Clinical review: humidifiers during non-invasive ventilation-key topics and practical implications. Crit Care. 2012;16:203.

21. Solomita M, Smaldone GC. Humidification and noninvasive ventilation. Respir Care. 2007:52:24-5.

22. Shelly MP, Lloyd GM, Park GR. A review of the mechanisms and methods of humidification of inspired gases. Intensive Care Med. 1988;14:1-9.

23. Burton JD. Effects of dry anaesthetic gases on the respiratory mucous membrane. Lancet (London, England). 1962;1:235-8.

24. Branson RD, Gentile MA. Is humidification always necessary during noninvasive ventilation in the hospital? Respir Care. 2010;55:209-16 (discussion 216)

25. Fontanari $P$, Burnet $H$, Zattara-Hartmann MC, Jammes $Y$. Changes in airway resistance induced by nasal inhalation of cold dry, dry, or moist air in normal individuals. J Appl Physiol. 1996;81:1739-43.

26. American Association for Respiratory Care, Restrepo RD, Walsh BK. Humidification during invasive and noninvasive mechanical ventilation: 2012. Respir Care. 2012;57:782-8.

27. Lellouche F, L'Her E, Abroug F, Deye N, Rodriguez PO, Rabbat A, et al. Impact of the humidification device on intubation rate during noninvasive ventilation with ICU ventilators: results of a multicenter randomized controlled trial. Intensive Care Med. 2014:40:211-9.

28. Lellouche F, Pignataro C, Maggiore SM, Girou E, Deye N, Taillé S, et al. Short-term effects of humidification devices on respiratory pattern and arterial blood gases during noninvasive ventilation. Respir Care. 2012:57:1879-86.

29. Lellouche F, Maggiore SM, Deye N, Taillé S, Pigeot J, Harf A, et al. Effect of the humidification device on the work of breathing during noninvasive ventilation. Intensive Care Med. 2002;28:1582-9.

30. Chiumello D, Chierichetti M, Tallarini F, Cozzi P, Cressoni M, Polli F, et al. Effect of a heated humidifier during continuous positive airway pressure delivered by a helmet. Crit Care. 2008;12:R55.

31. Ueta K, Tomita T, Uchiyama A, Ohta N, Iguchi N, Goto Y, et al. Influence of humidification on comfort during noninvasive ventilation with a helmet. Respir Care. 2013;58:798-804.

32. Scala R, Naldi M. Ventilators for noninvasive ventilation to treat acute respiratory failure. Respir Care. 2008;53:1054-80.

33. Baydur A, Behrakis PK, Zin WA, Jaeger M, Milic-Emili J. A simple method for assessing the validity of the esophageal balloon technique. Am Rev Respir Dis. 1982;126:788-91.

34. Akoumianaki E, Maggiore SM, Valenza F, Bellani G, Jubran A, Loring SH, et al. The application of esophageal pressure measurement in patients with respiratory failure. Am J Respir Crit Care Med. 2014;189:520-31.

35. Mauri T, Yoshida T, Bellani G, Goligher EC, Carteaux G, Rittayamai N, et al. Esophageal and transpulmonary pressure in the clinical setting: meaning, usefulness and perspectives. Intensive Care Med. 2016:42:1360-73.

36. Mojoli F, Chiumello D, Pozzi M, Algieri I, Bianzina S, Luoni S, et al. Esophageal pressure measurements under different conditions of intrathoracic pressure. An in vitro study of second generation balloon catheters. Minerva Anestesiol. 2015;81:855-64.

37. Yoshida T, Grieco DL, Brochard L. Guiding ventilation with transpulmonary pressure. Intensive Care Med. 2019;45:535-8.

38. Dres M, Rittayamai N, Brochard L. Monitoring patient-ventilator asynchrony. Curr Opin Crit Care. 2016;22:246-53.

39. Georgopoulos D, Prinianakis G, Kondili E. Bedside waveforms interpretation as a tool to identify patient-ventilator asynchronies. Intensive Care Med. 2006:32:34-47.

40. Thille AW, Rodriguez P, Cabello B, Lellouche F, Brochard L. Patient-ventilator asynchrony during assisted mechanical ventilation. Intensive Care Med. 2006;32:1515-22.

41. Grieco DL, Bitondo MM, Aguirre-Bermeo H, Italiano S, Idone FA, Moccaldo $A$, et al. Patient-ventilator interaction with conventional and automated management of pressure support during difficult weaning from mechanical ventilation. J Crit Care. 2018;48:203-10.

42. Costa R, Navalesi P, Antonelli M, Cavaliere F, Craba A, Proietti R, et al. Physiologic evaluation of different levels of assistance during noninvasive ventilation delivered through a helmet. Chest. 2005;128:2984-90.

43. Rittayamai N, Beloncle F, Goligher EC, Chen L, Mancebo J, Richard JCM, et al. Effect of inspiratory synchronization during pressure-controlled ventilation on lung distension and inspiratory effort. Ann Intensive Care. 2017:7:100.

44. Menga LS, Cese LD, Bongiovanni F, Lombardi G, Michi T, Luciani F, et al. High failure rate of noninvasive oxygenation strategies in critically ill subjects with acute hypoxemic respiratory failure due to COVID-19. Respir Care. 2021;66:705-14

45. Mercurio G, D'Arrigo S, Moroni R, Grieco DL, Menga LS, Romano A, et al. Diaphragm thickening fraction predicts noninvasive ventilation outcome: a preliminary physiological study. Crit Care. 2021;25:219.

46. Dangers L, Montlahuc C, Kouatchet A, Jaber S, Meziani F, Perbet S, et al. Dyspnoea in patients receiving noninvasive ventilation for acute respiratory failure: prevalence, risk factors and prognostic impact: a prospective observational study. Eur Respir J. 2018;52:1702637.

47. Menga LS, Grieco DL, Rosà T, Cesarano M, Delle Cese L, Berardi C, et al. Dyspnoea and clinical outcome in critically ill patients receiving noninvasive support for COVID-19 respiratory failure: post hoc analysis of a randomised clinical trial. ERJ open Res. 2021. https://doi.org/10.1183/ 23120541.00418-2021.

48. Ferrone G, Cipriani F, Spinazzola G, Festa O, Arcangeli A, Proietti R, et al. A bench study of 2 ventilator circuits during helmet noninvasive ventilation. Respir Care. 2013;58:1474-81.

49. Natalini D, Grieco DL, Santantonio MT, Mincione L, Toni F, Anzellotti GM, et al. Physiological effects of high-flow oxygen in tracheostomized patients. Ann Intensive Care. 2019;9:114.

\section{Publisher's Note}

Springer Nature remains neutral with regard to jurisdictional claims in published maps and institutional affiliations.

\section{Submit your manuscript to a SpringerOpen ${ }^{\circ}$ journal and benefit from:}

- Convenient online submission

- Rigorous peer review

- Open access: articles freely available online

- High visibility within the field

Retaining the copyright to your article

Submit your next manuscript at springeropen.com 